\title{
Childhood Grief and Loss
}

\author{
Aime Ferow, LPC Intern \\ Liberty University, United States
}

Doi: 10.19044/ejes.s.v6a1

URL:http://dx.doi.org/10.19044/ejes.s.v6a1

\begin{abstract}
Children experience grief and loss from death, divorce, parental incarceration, and similar situations of being placed in foster care or adoption. These youths may be challenged in recovery due to lacking the necessary life experience and coping skills. They may also lack the appropriate support networks to work through their grief as their remaining parent or family members may be too grieved to be of assistance. Peers, can even distance themselves out of inability to understand the experience. Children are at risk for developing psychological difficulties that can manifest into psychiatric disorders when lacking coping skills. Therefore, it is critical for parents, teachers, pastors, and other influential adults to recognize the risk factors associated with complicated or unresolved grief. It is also important to remember the child's developmental age and stage when considering how to help. Some therapy techniques have been found helpful such as motivational interviewing, therapy that also includes a parent or guardian, group therapy, and grief support groups. It is necessary for adults to develop open and honest lines of communication with the child, ensuring that he feels safe expressing how he feels. Lastly, helping in grief and loss can cause secondary trauma. Self-care is vital for anyone helping work the grieving process.
\end{abstract}

Keywords: Childhood, grief, loss, trauma.

\section{Introduction:}

The Social Security Administration reported " 2.5 million children under the age of 18 [that] have experienced the death of a parent in the United States" (Koblenz, 2015, p. 203). Additionally, 700,000 children were in foster care in 2010, with 70,000 awaiting adoption (Fineran, 2012, p. 370). Currently over 2.7 million children have at least one parent who is incarcerated in America (youth.gov, 2016).

Children experiencing loss without the necessary skills or supports are more prone to develop psychological issues of grief and loss. School functioning is impaired due to the struggle to focus or concentrate, leading to 
the feelings of failure. They may begin to withdraw from social interactions with their peers, become anxious or preoccupied with death and loss (SAMHSA, 2014). This paper will examine losses by death, incarceration, fostering and adoption; the effects on children and adolescents; ways that parents, teachers, counselors, and other helping professionals can most effectively help them; and the ethical and legal considerations.

\section{Background Death}

The death of a loved one can be devastating at any age. Adults are more adept to handling loss than children due to life experiences and higher order thinking. Research suggests that more severe psychological difficulties are experienced by children who loses a parent before age three. Children through adolescence may experience increased difficulties in processing the loss for several reasons. Dependency on the remaining parent or caregiver, less peer support, and undeveloped cognitive verbal skills to express thoughts or feelings are a few (Cerniglia, Cimino, Ballarotto, \& Monniello, 2014). Older adolescents experiencing grief and loss may find it challenging to "fit in" with peers if they are the only ones experiencing parental loss. Feeling shunned or isolated because peers lack understanding or are uncomfortable talking about death may happen (LaFreniere \& Cain, 2015).

Sibling loss can be more detrimental. Usually the sibling relationship is the longest relationship in one's life. Siblings help one another develop interpersonal skills, self-regulation, and kinship. Same-sex siblings are usually closer and are more affected by sibling loss, especially if both are female. This may be because female siblings develop a closer, more intimate bond than male siblings (Fletcher, Mailick, Song, \& Wolfe, 2013). The surviving children must re-evaluate and adjust to their new roles in the family. Because their parents are also grieving the loss of the child, they may feel as if they must grieve on their own or that their grief is overlooked. Their parents may become overly protective and restrictive because of their feelings of failure in protecting the child that died (Machajewsk \& Kronk, 2013).

Cause of death and the child's perception of death are important aspects to consider in childhood grief and loss. According to Kaplow, Howell, and Layne (2014), deaths that are sudden, such as homicide, suicide, or an accidental death, are related to prolonged or complicated grief. Violent deaths are associated with increased levels of anxiety, depression, and maladaptive grief. If the child witnesses the event, memories can be triggered throughout his lifetime, resulting in traumatic grief or posttraumatic stress disorder (PTSD) (SAMHSA, 2014). In the case of a prolonged illness or anticipated death, children over the age of seven may experience "significantly higher levels of maladaptive grief and PTSS [posttraumatic stress syndrome] than 
children bereaved by a sudden, natural death" (Kaplow, Howell, \& Layne, 2014, p. 47), which may be due to witnessing the illness or the suffering of their loved ones.

\section{Foster Care and Adoption}

Nonfinite losses are "losses that slowly occur over time and have an anticipatory nature... is continuous in form, existing in the past, present and future" (Fineran, 2012, p. 370). Children who are in the foster care system are often in a state of limbo with anticipatory grief, due to the unexpectedness of the foster care system. Many hope to be reunited with their family and are repeatedly disappointed by their parent's instability and inability to care of them. Foster care workers concurrently plan to re-establish the family while simultaneously look for permanent adoption, during which time the children are bounced from home to home. These children suffer multiple repeated losses including: loss of birthparents and birth family; loss of status; loss of ethnic, racial, and genealogical belonging or connectedness; loss of stability within a family dynamic; and a loss of personal identity (Fineran, 2012).

\section{Incarceration and Mental Instability}

Children who have one or both parents incarcerated experience similar losses as children of dead parents or those in the foster care system. Similarly, "children whose parent is mentally unstable, particularly a depressed mother, is a solid risk factor for possible psychopathological development" (Trumbo, 2019). Additionally, they contend with the stigma of having a parent in prison or who is mentally ill. These children may have fears or increased feelings of shame, with grief, as a result of being told they will turn out to be "just like their parent" (youth.gov, 2016).

Regardless of the type of loss, these children's lives are disrupted with interference in developmental progresses and the ability to adapt to the new normal. Problematic grief, mental health problems, exposure to negative events, and negative self-esteem are experienced (Ayers, et al., 2014). This hinders their abilities to develop and maintain intimate relationships, to cope with other stressful life events, or to fulfill developmental tasks. Failure to maintain focus in learning causes falling behind in schooling while increasing risk of dropout (Fletcher, Mailick, Song, \& Wolfe, 2013).

Age at the time of loss is significant as stated by Cerniglia, Cimino, Ballarotto, and Monniello (2014), "the earlier the loss occurs, the more likely it is that the psychopathological symptoms will persist over time.... [and] may bring about a fivefold risk of developing psychiatric disorders in later life" ( $p$. 6). These children often vacillate between managing their own needs and desire and those of the other family members (Muselman \& Wiggins, 2012). Lacking supports and guidance, childhood grief and loss can lead to 
"dysphoria, depression, generalized anxiety, separation anxiety, PTSD, behavioral problems, and other generalized symptoms" (Machajewsk \& Kronk, 2013, p. 445).

\section{Special Considerations}

Caregivers and other adult helping professionals must know the developmental stage of the child and their perceptions concerning death and loss. Resilience factors such as peers, parental relationships, verbal skills, and metacognitions are stronger for older adolescents than for younger children (Cerniglia, Cimino, Ballarotto, \& Monniello, 2014). Social and cultural concerns are important to consider as well. During the adolescent stage, children develop their role identities, which may need to be redefined due to a significant loss (Muselman \& Wiggins, 2012).

\section{Age and Stage}

Even in infancy, babies can sense when their caregivers are grieving. They may become more irritable, change eating or sleeping patterns, or cry more. If they do not feel safe and assured, they may become withdrawn (Machajewsk \& Kronk, 2013). Babies benefit from being in familiar surroundings and feeling secure.

Toddlers and preschoolers, who function egocentrically, may believe that they are the cause of the loss and feel guilty. It is also not unusual for a child to regress developmentally, become clingy, or throw tantrums. To better understand their thoughts and feelings, caregivers should watch them play (or play with them), as "play demonstrates the child's understanding of his or her world" (Machajewsk \& Kronk, 2013, p. 445). If the child asks questions, honest and age appropriate answers will help with the grieving process.

It is not uncommon for developmental regression to also occur for school-age children. They may also develop somatic symptoms and become angry or aggressive. They could begin to isolate, their school performance may decline, or they may engage in risky behaviors such as drug or alcohol use (SAMHSA, n.d.). Suicide is a major concern for this age group. It is helpful to talk to them about the person they lost, to sustain the memories. Teen support groups may provide an outlet for them to express their grief. Even though some of their peers may shy away from them, a teen's peers remain critical to his support system. Adolescents who are grieving often look to their peers for support and to feel "normal". Their peers serve as a refuge while the family is enshrouded with grief (LaFreniere \& Cain, 2015).

Many of these children have extra responsibilities, especially if the loss creates a single parent household. Older children may need to help care for younger siblings or find jobs to contribute financially. They may feel they must protect the family and be reluctant to talk about their home life. In the 
cases of foster care and incarceration, the children are allowed minimal contact, if any, with their parent, yet they still love them and desire to have a relationship with them. Shame and fear of judgement may prevent these children from being open (SAMHSA, n.d.).

\section{Social and Cultural Factors}

Death is an uncomfortable topic for most Americans. Grieving youth may find that their friends treat them differently or avoid them because of this fact. In a study based on interviews of adults who experienced parental loss as children, one of the most common experiences was that "sympathy expires before grieving does", they felt as if they were expected to "get over it and move on" (Koblenz, 2015, p. 216). One of the most helpful resources are other youths who have similar experiences and can relate to one another.

Spirituality is helpful for the grieving process. When life does not make sense, spiritual belief provides hope where there may seem to be none. Spiritual concepts related to death and the afterlife provide a basis on which to comprehend that eventually everyone will die, and it is not reversible; however, there is hope and peace in what comes after (Pond, 2013). Religious communities such as churches provide reliable support by having a care ministry or staff who are trained to provide grief support to children, adolescents, and their families.

What is considered normal grief reaction to one may be considered abnormal by another depending on one's cultural upbringing. This is another factor to consider when determining a course of action to assist a youth who is grieving a loss. Helping professionals may need to seek consultation for the best ways to assist children from other cultures (SAMHSA, 2014).

\section{Red Flags}

Children experiencing traumatic grief may have nightmares or intrusive thoughts about the incident. They may have excessive guilt, believing that they if they would have done something differently, the incident would not have happened (SAMHSA, 2014). Grieving children tend to be more anxious, withdrawn, depressed, have more difficulties in school, and their school performance declines (Ayers, et al., 2014). Some children have short, acute grief responses, others may have prolonged grief, and some may show no visible signs of grief at all. Anniversary reactions are also common (Koblenz, 2015). Caregivers and other helping professionals need to be sensitive to how the child responds and provide the emotional support necessary to help avoid complicated grief. 


\section{Effective Interventions}

The grieving process "is not linear, but cyclic, reappearing at different life events, developmental stages, or as the result of memory triggers" (Pond, 2013, p. 116). Part of the process is moving from the pain to focusing on living. While there are many counseling techniques and steps to processing grief, it is important to allow a child to help determine the course of their own grief therapy (Koblenz, 2015). Grief is a lifelong process and children need to learn how to adapt to life without their loved one. Part of the responsibility of caregivers and helping professionals is that of helping these children process their feelings of loss, remembering the one who has been lost, and embracing the opportunities ahead.

Individual and group therapies have been found effective for grieving adolescents. Therapy that focuses on social skills training and relaxation aid in reducing depressive symptoms. Motivational interviewing (MI) can be used to help an adolescent accept the reality of the loss and begin adapting to the changes in his identity and home-life because of the loss. When using MI, the counselor is empathic to the child's feelings and "rolls with the resistance" by reflecting feeling, validating his thoughts and concerns (Fineran, 2012, p. 372).

Creative or expressive therapy such as art, music, drama, and writing help a child express that which is difficult to say. Exercises such as unfinished sentences or writing a letter to the deceased/absent loved one help with closure and recognizing how life has changed. These techniques also help connect feelings, thoughts, and behaviors (Fineran, 2012). Scrapbooking, memory boxes, and other spiritual rituals help with maintaining memories. Counselors can foster and atmosphere of openness and understanding, while teaching healthy ways of expressing negative emotions. It is important to explain that feelings are neither good nor bad, but some responses to those feelings are unacceptable. Group therapy provides a safe place to express these emotions and feel a sense of normalcy through the universality of their experiences (Ayers, et al., 2014). Some children, and even some adults, find it difficult to pinpoint what they are feeling. Feeling faces can be used to help them learn about their own emotions and be able to better understand what others are feeling as well (SAMHSA, 2014).

Psychoeducation and Cognitive Behavioral Therapy (CBT) are useful for teaching coping skills, managing stress reactions, recognizing internal strengths, and identifying outside sources of support. Cognitive reframing and cognitive affect regulation are techniques that are useful for changing negative automatic thoughts and feelings. Asking questions pertaining to the event such as, "Could you have done anything to prevent it?" or "What do you think life will be like in the future?" to help identify any distorted thinking (SAMHSA, 2014, p. 37). Having the child talk about the loss facilitates the mourning 
process, allows for "addressing ambivalent feelings" about the person, and "preserves positive memories" (SAMHSA, 2014, pp. 42-43).

During adolescence, children are forming their identities and seeking independence. Death and loss hinders these processes, often making them feel as if they have lost any control. Psychoeducational groups help them to redefine who they are in the aftermath of the loss, and to become empowered (Fineran, 2012). Oftentimes adolescents will take on more responsibility than they can or should have to after a loss. This is in part due to having a caregiver who is also grieving. Part of empowering them is helping to recognize what is within their realm of control and what is not (Ayers, et al., 2014).

Sensitivity to cultural and spiritual background is imperative. Adolescents may experience a crisis of faith or spiritual growth, depending on how their loss is perceived. Counselors can be instrumental in the grief process by "creating a safe space for adolescents to make meaning out of loss and by drawing upon their spiritual worldviews... finding solace in the midst of their grief" (Muselman \& Wiggins, 2012, p. 5).

Grieving children need to be able to identify the triggers for their grief and depression. Caregivers can help prepare them for anniversary reactions or other loss reminders. Counselors can provide techniques that are helpful during these challenging times so that they are easier to manage. Finally, these children and their families need to understand that their experiences during these times are to be expected and are normal, and that it is acceptable to feel as they do (SAMHSA, 2014).

\section{Working with Caregivers, Teachers, Clinicians, or Other Helping Professionals}

Caregivers, teachers, clinicians, and other helping professionals play a significant role in helping a child through a time of grief. Collaboration is the key to being able to best help these children to successfully navigate their bereavement (SAMHSA, n.d.). Parents may need to attend counseling, grief support groups, and/or parenting classes to best learn to manage their own grief while helping their children.

Children need help learning how to cope with these several types of loss, and their caregivers have the most influence over how they manage their grief. However, oftentimes a child's caregiver is struggling to process his/her own grief. For this reason, some of the most effective interventions involve both the child and the caregiver.

It is important for caregivers to recognize that their grief may be very unlike that of the child's. Their relationship with the deceased/absent was different, their reaction to the loss is different, their ability to process the event is different. Children cannot be expected to grieve like the adults around them. Caregivers who are fostering or adopting need to recognize and adapt to any 
cultural or spiritual differences (SAMHSA, 2014). Counselors and other helping professionals can help this process by teaching parents and caregivers how to recognize grief response in their children and about the children's cultural or spiritual background.

It is essential that parents/caregivers spend one-on-one time with their children, especially following the loss. Children who are given the time to spend with their caregivers in which they could talk openly about their feelings tend to have more positive outcomes than those who are not afforded this time (Koblenz, 2015). This reciprocal relationship is also beneficial to the caregiver's mental health (Ayers, et al., 2014). Counselors can help foster effective listening and communication skills between the children and their caregivers.

Caregivers are often the role models for how children express their grief. It is important that parents are honest with the youths. Studies reveal that in the case of suicide, children who were lied to about the circumstances of a death are at a greater risk of developing psychiatric symptoms (Kaplow, Howell, \& Layne, 2014). Children will ask questions; they should be answered as honestly and at an age appropriate level. If their loss involves the loss of their parents, they should be informed as to whom will be caring for them.

Teachers, clinicians, and other helping professionals can aid caregivers in identifying needs and behaviors that may be of concern. They should be aware of the developmental stage of the child (Machajewsk \& Kronk, 2013). Attending continuing educational classes ensures that the stay apprised of the best therapeutic techniques for childhood grief and attending to their families. Factors that foster the therapeutic process are the child's understanding of the need for help, the willingness to attend, the therapeutic alliance, and flexibility in therapy (Koblenz, 2015). They should have knowledge of community resources that would be beneficial for referrals. These professionals are also obligated to look for signs of abuse and report any suspected abuse to the proper authorities.

\section{Resources for Teachers and Other Educators}

Because schools are a crucial source of support for children, it is imperative that teachers have the skills and tools necessary to help develop or increase the resiliency of their students. Teachers who can recognize the signs of a student who is struggling to make sense of their loss are able to help reduce the effects of the traumatic experience and aid in their ability to develop a healthier response (Texas Education Agency, 2019). Several training programs have been developed to help educators understand how to intervene and foster resiliency in their students who have experienced trauma or grief. 
The Cognitive-Behavioral Intervention for Trauma in Schools (CBITS) is a curriculum designed to help children who have experienced severe traumas, including abuse, natural disasters, and significant losses. It also focuses on the ethnic or cultural diversity of the student. UCLA TraumaGrief curriculum provides psychoeducation, emotional awareness, identification of trauma or grief symptoms, coping skills development, and provides information for sources of support. The National Child Traumatic Stress Network has resources for educators, such as the Child Trauma Toolkit for Educators, designed to help them when working with these children and their families. These, along with many other resources, will help school staff and educators better understand the experience of grief and loss of their students. It will give them the ability mitigate the risk of developing an unhealthy response to their grief, which could result in further psychological diagnoses such as major depression, anxiety, or prolonged grief (Texas Education Agency, 2019).

All professionals should also be aware of secondary trauma and ensure that they take care of themselves to be able to care for these children and their families. Self-care is vital, especially when working with grief and loss. In the case of countertransference, helping professionals should either consult with colleagues or seek counseling for themselves (Fineran, 2012).

\section{Ethics and Legal Issues}

Teachers, clinicians, and the other helping professionals must be aware of the proven interventions, but also know the ethical and legal concerns of working with parents and children. This section will explore some of the areas that must be considered when working with this population. Every helping professional must be aware of the specific codes of ethics for their profession and laws that govern them.

\section{Informed Consent}

Informed consent provides the client with information concerning the types of service, goals, risks, limitations of services, the professional's credentials, and in counseling, the therapeutic approach. For those who are unable to consent, this information is still provided; however, a parent or legal guardian must give written consent for treatment. Furthermore, the information is to be "developmentally and culturally appropriate" (ACA Counseling Association, 2014, §A.2.c.).

Professionals must consider who is authorized to consent to any medical or psychological treatment of a child. These persons may include parents, grandparents, adult siblings, adult aunts or uncles, a court, a peace officer, or an adult who is "responsible for the actual care, control, and possession of a child under the jurisdiction of a juvenile court or committed 
by a juvenile court to the care of an agency of the state or country" (Texas State Legislature, 2013, Title 2, Subtitle A, Chapter 32, Subchapter A, Section 32.001). There are some things the child may consent to themselves without an adult. For example, in Texas a child may consent to counseling for suicide prevention, chemical addiction or dependency, or for sexual, physical or emotional abuse (Texas State Legislature, 2013). In these instances, it is imperative for professionals to know when it is appropriate and legal to break confidentiality and advise the child's guardian of the treatment. Sometimes obtaining other legal documents, such as guardianship or divorce decrees, which designate to whom a child's information may be shared, is also necessary.

Informed consent may include the necessity to obtain written permission to share information with other professionals. It is beneficial to the child and his family when helping professionals work together. School counselors are responsible for addressing multiple concerns for their students, including their academic progress, career potentials, and their various emotional needs. While they do not provide a diagnosis to the students, they must be aware of how any emotional disturbances will affect their academic success. For the best results, they coordinate with the entire education team to provide students with the necessary support services (American School Counselor Association, 2016, § A.1).

\section{Confidentiality and Other Considerations}

Confidentiality of the child and his family is also important. Helping professionals, such as school counselors, are required to ensure their students understand the limits of confidentiality. When it is not possible to obtain informed consent from the student, the counselor may act on behalf of the student in the best interest of the student. According to the National Education Association (NEA), teachers are expected to make a "reasonable effort to protect the student from conditions harmful to learning or to health and safety" (2018, p. 437). School counselors must maintain the student's confidentiality unless otherwise legally required or if there is enough reason to believe the student is at risk of "serious and foreseeable harm". (American School Counselor Association, 2016). In these instances, the counselor may break confidentiality and advise the child's guardian of the treatment.

Parents or guardians should be aware of the types of treatment and the associated charges incurred. This should be provided in their native language and in a way that is easily understood. When a child is being treated as part of a court order or custody agreement, the counselor must have a current copy of the agreement or court order as part of the client's record. Counselors are required to report all instances of abuse or neglect of minors (Texas DHSH, 2015). 


\section{Conclusion:}

Millions of children experience grief and loss each year. Grief, when not managed in a healthy manner, can become complicated and prolonged. Caregivers are often affected by grief at the same time, so it may be necessary for these children and their families to seek outside sources for assistance in adjusting to life after loss. Counselors and other helping professionals must stay apprised of effective therapeutic techniques, community resources, and the ethical and legal considerations for treating minors and their caregivers. Teachers, once aware of a grief/loss incident, are responsible for attending to and fostering the well-being of their students to the best of their ability. This includes paying attention to the signs and symptoms of grief and loss, making the necessary accommodations to their learning, conferences with the child's caregivers, and helping to ensure that the child's experience in the classroom is as normal as possible and a safe place for him.

\section{References:}

1. ACA Counseling Association. (2014). 2014 ACA Code of Ethics. Retrieved from http://www.counseling.org

2. American School Counselor Association. (2016). ASCA ethical tandards for school counselors. Retrieved from American School Counselor Association: https://www.schoolcounselor.org/asca/media/asca/Ethics/EthicalStan dards2016.pdf

3. Ayers, T. S., Wolchik, S. A., Sandler, I. N., Twohey, J. L., Weye, J. L., Padgett-Jones, S., . . . Kriege, G. (2014). The family bereavement program: Description of a theory-based prevention program for parentally-bereaved children and adolescents. OMEGA - Journal of Death and Dying, 68(4), 293-314. doi:http://dx.doi.org.ezproxy.liberty.edu/10.2190\%2FOM.68.4.a

4. Cerniglia, L., Cimino, S., Ballarotto, G., \& Monniello, G. (2014). Parental loss during childhood and outcomes on adolescents' psychological profiles: a longitudinal study. Current Psychology, 33(4), 545+. $\quad$ Retrieved from http://go.galegroup.com.ezproxy.liberty.edu/ps/i.do?p=ITOF\&u=vic_ liberty\&id=GALE $\mid$ A390728514\&v=2.1\&it=r\&sid=summon\&authCo unt $=1$

5. Fineran, K. R. (2012). Helping foster and adopted children to grieve the loss of birthparents. The Family Journal, 20(4), 369-375. doi:http://dx.doi.org.ezproxy.liberty.edu/10.1177\%2F106648071245 1230

6. Fletcher, J., Mailick, M., Song, J., \& Wolfe, B. (2013). A sibling death in the family: Common and consequential. Demography, 50(3), 803- 
826. doi:http://dx.doi.org.ezproxy.liberty.edu/10.1007/s13524-012$0162-4$

7. Kaplow, J. B., Howell, K. H., \& Layne, C. M. (2014). Do circumstances of the death matter? Identifying socioenvironmental risks for grief-related psychopathology in bereaved youth. Journal of Traumatic Stress, 42-49. doi:10.1002/jts.21877

8. Koblenz, J. (2015). Growing from grief. OMEGA - Journal of Death and Dying 203-230. doi:http://dx.doi.org.ezproxy.liberty.edu/10.1177\%2F003022281557 6123

9. LaFreniere, L., \& Cain, A. (2015). Peer interactions of parentally bereaved children and adolescents. OMEGA - Journal of Death and Dying, 72(2), 91-118. doi:http://dx.doi.org.ezproxy.liberty.edu/10.1177\%2F003022281557 4829

10. Machajewsk, V., \& Kronk, R. (2013). Childhood grief related to the death of a sibling. The Journal for Nurse Practitioners, 9(7), 443-448. doi:http://dx.doi.org.ezproxy.liberty.edu/10.1016/j.nurpra.2013.03.02 0

11. Muselman, D. M., \& Wiggins, M. I. (2012). Spirituality and loss: approaches for counseling grieving adolescents. Counseling and Values, 57(2), 229+. Retrieved from http://go.galegroup.com.ezproxy.liberty.edu/ps/i.do?p=ITOF\&u=vic_ liberty\&id=GALE $\mid$ A306753181\&v=2.1\&it=r\&sid=summon\&authCo unt=1\#

12. National Education Association. (2018). Code of ethics of the education profession. Retrieved from NEA Handbook: http://www.nea.org/assets/docs/Code_of_Ethics_NEA_Handbook_20 18.pdf

13. Pond, S. K. (2013). Childhood grief and the church's response. Journal Of Research On Christian Education, 22(2), 113-138. doi:10.1080/10656219.2013.808980

14. SAMHSA. (2014). The Courage to Remember: Childhood Traumatic Grief Curriculum Gude. Rockville, MD: SAMHSA, Center for Mental Health Services.

15. SAMHSA. (n.d.). Tips for talking with and helping children and youth cope after a disaster or traumatic event: A guide for parents, caregivers and teachers. Retrieved from SAMHSA.gov: https://store.samhsa.gov/shin/content/SMA12-4732/SMA12-4732.pdf

16. Texas DHSH. (2015). Code of Ethics. Retrieved from Texas State Board of Examiners of Professional Counselors - Rules and Regulations: 
http://texreg.sos.state.tx.us/public/readtac\$ext.ViewTAC?tac_view=5 $\& \mathrm{ti}=22 \& \mathrm{pt}=30 \& \mathrm{ch}=681 \& \mathrm{sch}=\mathrm{C} \& \mathrm{rl}=\mathrm{Y}$

17. Texas Education Agency. (2019). Grief informed and trauma informed practices. Retrieved from Texas Education Agency: https://tea.texas.gov/About_TEA/Other_Services/Mental_Health/Grie f_Informed_and_Trauma_Informed_Practices/

18. Texas State Legislature. (2013). Family Code. Retrieved from Texas Constitution and Statutes: http://www.statutes.legis.state.tx.us/Docs/FA/pdf/FA.32.pdf

19. Texas State Legislature. (2015). Family Code. Retrieved from Texas Constitution and Statutes: $\mathrm{http} / / / \mathrm{www}$.statutes.legis.state.tx.us/?link=FA

20. Trumbo, C. (2019, April 28). PhD., LPC. (A. Ferow, Interviewer) youth.gov. (2016). Tip sheet for providers: Supporting children who have an incarcerated parent. Retrieved from youth.gov: http://youth.gov/sites/default/files/COIP-TipSheetProviders_Final.pdf 